\title{
Pelatihan Pembuatan Sabun Cuci Piring sebagai Upaya Pemberdayaan Ibu-ibu PKK di Desa Kutuwetan Kabupaten Ponorogo
}

\section{(Dish Soap Making Training as an Empowerment Effort for PKK Ladies in Kutuwetan Village, Ponorogo Regency)}

\author{
Nur Ihda Farikhatin Nisa ${ }^{1 *}$, Dyan Hatining Ayu Sudarni ${ }^{2}$, Saifulloh ${ }^{3}$ \\ ${ }^{1,2}$ Program Studi Teknik Kimia, Fakultas Teknik, Universitas PGRI Madiun \\ ${ }^{3}$ Program Studi Sistem Informasi, Fakultas Teknik, Universitas PGRI Madiun \\ Jl. Auri No. 14-16 Kota Madiun
}

\begin{tabular}{l} 
ARTICLE INFO \\
\hline Article history \\
Received : 20 April 2021 \\
Revised : 30 Mei 2021 \\
Accepted : 08 Juni 2021 \\
DOI : \\
$\underline{\text { https://doi.org/10.33366/jast. }}$ \\
$\underline{\text { v5i1.2378 }}$
\end{tabular}

Keywords :

dish soap; empowerment; production; training.

*e-mail corresponding author : nurihda_fn@unipma.ac.id

\section{PENERBIT}

\section{UNITRI PRESS}

Jl. Telagawarna, Tlogomas-

Malang, 65144, Telp/Fax: 0341565500

\section{cc) (†) (?)}

This is an open access article under the Creative Commons AttributionShareAlike $4.0 \quad$ International License. Any further distribution of this work must maintain attribution to the author(s) and the title of the work, journal citation and DOI. CC-BY-SA

\begin{abstract}
ABSTRAK
Dalam kehidupan sehari-hari, sabun merupakan salah satu barang yang sangat dibutuhkan oleh manusia baik untuk menjaga kebersihan badan maupun kebersihan lingkungan sekitar. Tingginya minat masyarakat terhadap sabun khususnya sabun cuci piring, menjadikan terbukanya peluang usaha untuk memproduksi sabun untuk memenuhi kebutuhan masyarakat tersebut. Pemberdayaan masyarakat terutama kelompok ibu-ibu PKK untuk memproduksi sabun cuci piring bisa dilakukan karena pembuatan sabun cuci piring yang relatif mudah dipelajari dan diproduksi. Akan tetapi, pengetahuan masyarakat tentang bahan kimia dan proses produksi sabun cuci piring masih sangat minim. Tujuan dari kegiatan pengabdian kepada masyarakat ini adalah untuk memberikan wawasan tentang peluang usaha rumahan dan keterampilan pembuatan sabun cuci piring pada ibu-ibu PKK. Kelompok mitra kegiatan ini adalah ibu-ibu PKK di Desa Kutuwetan Kabupaten Ponorogo. Dengan kegiatan ini diharapkan mampu meningkatkan kesejahteraan masyarakat khususnya dalam bidang ekonomi serta menumbuhkan kesadaran dan kemandirian dalam berwirausaha. Metode yang digunakan dalam kegiatan pengabdian bagi masyarakat ini meliputi koordinasi dengan mitra, penyuluhan, pelatihan pembuatan sabun cair serta evaluasi dan tindak lanjut. Hasil dari kegiatan pengabdian kepada masyarakat ini yaitu berupa produk sabun cuci piring yang telah dimasukkan kemasan dan dibagikan pada warga sekitar. Selain itu, tercapainya kelompok mitra yang telah memiliki keterampilan dalam pembuatan sabun cuci piring.
\end{abstract}

Cara Mengutip : Nisa, N. I. F., Sudarni, D.H.A., Saifulloh, S. (2021). Pelatihan Pembuatan Sabun Cuci Piring sebagai Upaya Pemberdayaan Ibu-ibu PKK di Desa Kutuwetan Kabupaten Ponorogo. JAST : Jurnal Aplikasi Sains dan Teknologi, 5(1), 53-59. doi:https://doi.org/10.33366/jast.v5i1.2378 


\section{PENDAHULUAN}

Dalam kehidupan sehari-hari, salah satu barang yang sangat dibutuhkan oleh manusia baik untuk menjaga kebersihan badan maupun kebersihan lingkungan sekitar adalah sabun[1]. Upaya pemenuhan kebutuhan manusia terhadap sabun khususnya sabun cuci piring dapat dilakukan dengan melakukan pemberdayaan ibu-ibu PKK. Pemberdayaan perempuan di bidang ekonomi memiliki andil besar dalam peningkatan perekonomian keluarga [2]. Upaya yang dapat dilakukan untuk meningkatkan perekonomian keluarga adalah dengan melakukan kegiatan usaha produktif rumah tangga [3]. Selain itu, kegiatan pemberdayaan ini dapat menumbuhkan jiwa kemandirian dalam berwirausaha serta memperluas lapangan kerja [4]-[6].

PKK RT 2 dan RT 3 merupakan wadah pemberdayaan perempuan di desa Kutuwetan Kabupaten Ponorogo. Latar belakang pendidikan dari anggota PKK tersebut beragam mulai lulusan SMA hingga universitas. Dimana sebagian besar dari ibu-ibu anggota PKK ini memenuhi kebutuhan perekonomian keluarga dengan membantu usaha suami di bidang pertanian.

Universitas memiliki peranan penting untuk turut serta membantu meningkatkan perekonomian keluarga dari masyarakat sekitar. Salah satu upaya yang dapat dilakukan adalah dengan memberikan program pelatihan pembuatan sabun cuci piring. Sabun merupakan kebutuhan pokok manusia tetapi bukan kebutuhan pokok primer [7], [8]. Sabun dibuat secara kimia melalui reaksi saponifikasi dengan bahan yang bisa diperoleh di toko kimia [9]. Alat dan bahan yang diperlukan dalam pembuatan sabun cuci piring sangat sederhana sehingga ibu-ibu PKK di desa ini dapat menjadikan keterampilan baru yang mereka dapat untuk merintis usaha rumahan. Selain dapat menambah pendapatan keuangan keluarga, usaha ini juga dapat menghemat pengeluaran rumah tangga [10].

Tujuan utama kegiatan pengabdian kepada masyarakat ini adalah memberikan pengetahuan dan keterampilan kepada ibu-ibu PKK di Desa Kutuwetan Kabupaten Ponorogo untuk memproduksi sabun cuci piring sehingga dapat meningkatkan perekonomian keluarga.

\section{METODE KEGIATAN}

Adapun metode yang digunakan dalam kegiatan pengabdian kepada masyarakat di desa Kutuwetan Kabupaten Ponorogo adalah sebagai berikut:

\section{- Koordinasi dengan mitra}

Koordinasi dengan mitra dilakukan dalam berbagai bentuk baik sebelum kegiatan maupun sesudah kegiatan pengabdian kepada masyarakat. Sebelum kegiatan ini, tim pengabdi menggali beberapa informasi dari kelompok mitra tentang berbagai permasalahan yang dihadapi warga yang mungkin bisa diselesaikan oleh tim pengabdi. Sampai pada akhirnya disepakati tentang kegiatan pembuatan sabun cuci piring untuk membantu ibu-ibu meningkatkan perekonomian keluarga, waktu serta lokasi pelaksanaan kegiatan ini. 


\section{- Pembelian alat dan bahan}

Sebelum kegiatan ini, tim pengabdi telah menyiapkan alat dan bahan yang dibutuhkan untuk proses pembuatan sabun cuci piring. Alat dan bahan yang dibutuhkan diantaranya baskom, pengaduk kayu, sendok, gelas ukur, kain lap, timbangan, wadah plastik kecil, wadah plastik besar, corong, botol plastik, label, sodium sulfat, texapon, comperland, foam booster, fixatif, parfum, pewarna, EDTA, dan aquades.

\section{- Penyuluhan}

Kegiatan Penyuluhan dilakukan untuk memberikan wawasan kepada kelompok mitra tentang peluang usaha rumahan dan proses pembuatan sabun cuci piring. Kegiatan ini dilakukan dirumah salah satu warga kelompok mitra. Tim pengabdi juga memberikan modul kepada kelompok mitra sehingga memudahkan mereka dalam mengikuti kegiatan pelatihan.

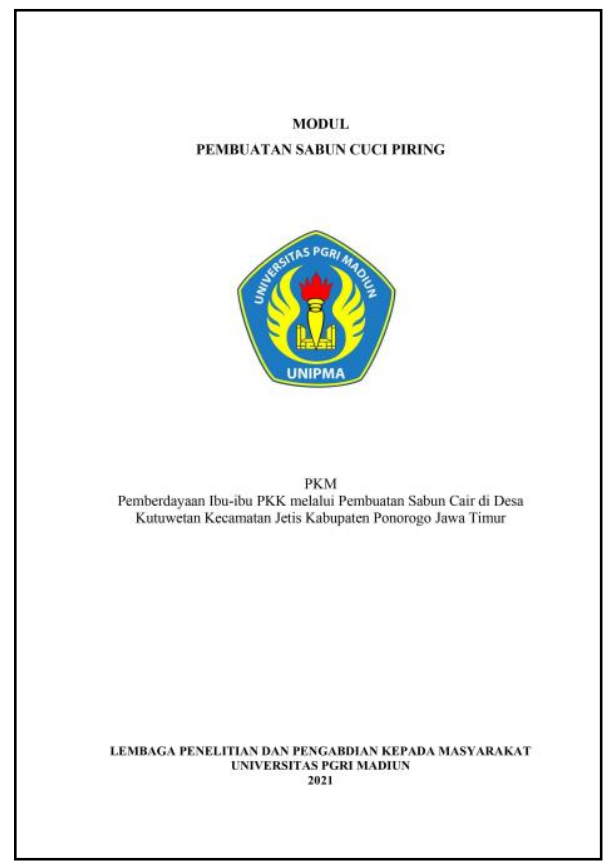

Gambar 1. Modul pelatihan

\section{- Pelatihan}

Pelatihan dilakukan dengan mempraktikkan secara langsung proses pembuatan sabun cuci piring. Kelompok mitra berpartisipasi aktif dalam kegiatan ini dengan turur serta mempraktikkan sesuai dengan arahan yang diberikan oleh tim pengabdi. Dalam praktik ini, kelompok mitra juga diperbolehkan melakukan sesi tanya jawab mengenai hal-hal yang kurang dipahami dalam proses pembuatan sabun cuci piring.

- Evaluasi dan tindak lanjut

Evaluasi kegiatan pengabdian kepada masyarakat ini dilakukan pada saat kegiatan berlangsung maupun sesudah kegiatan. Pada saat kegiatan berlangsung, tim pengabdi melakukan evaluasi tentang partisipasi aktif peserta pelatihan dalam bentuk tanya jawab. Tim pengabdi juga menerima saran dan kritik dari peserta pelatihan terhadap pelaksanaan kegiatan ini. Saran dan kritik mereka sampaikan dalam sesi tanya jawab. 
Saran yang mereka sampaikan diantaranya agar tim pengabdi terus melanjutkan program pengabdian ini dengan memberikan pelatihan dan penyuluhan dalam bidang lain yang daoat meningkatkan kesejahteraan dari masyarakat Kutuwetan. Dari evaluasi ini diperoleh bahwa kelompok mitra sangat antusias terhadap kegiatan ini. Hal ini disebabkan karena beberapa alasan diantaranya mereka belum pernah memperoleh kegiatan penyuluhan dan pelatihan pembuatan sabun cuci piring, materi pelatihan yang mudah dimengerti dan dipraktikkan sendiri, dan waktu kegiatan yang tidak mengganggu kegiatan rumah tangga. Sedangkan evaluasi yang dilakukan sesudah kegiatan berupa monitoring sampai kelompok mitra benar-benar mahir mempraktikkan sendiri.

\section{KARYA UTAMA}

Kelompok mitra dari kegiatan ini yakni ibu-ibu PKK diberikan pengetahuan dan keterampilan proses pembuatan sabun cuci piring dan cara pengemasannya. Adapun langkah-langkah pembuatan sabun cuci piring adalah sebagai berikut:

1. Mencampurkan sodium sulfat dan texapon dalam baskom lalu mengaduk 2 bahan tersebut sampai rata dan warna berubah menjadi putih

2. Menambahkan secara perlahan-lahan setengah bagian aquades yang telah disiapkan

3. Menambahkan comperland lalu mengaduknya sampai rata dan tidak terbentuk gumpalan

4. Menambahkan sisa air yang tersedia

5. Memasukkan foam boaster dalam adonan sedikit demi sedikit sampai larutan mengental. Lalu menambahkan EDTA dan fixatif

6. Mencampurkan dalam adonan tersebut parfum dan pewarna. Setelah itu produk yang dihasilkan dikemas dengan memasukkannya dalam botol plastik yang telah diberi label.

Kegiatan penyuluhan dan pelatihan pembuatan sabun cuci piring ditunjukkan pada Gambar 2. Peserta dalam kegiatan ini adalah ibu-ibu PKK perwakilan dari RT 02 dan RT 03 yang berjumlah 20 orang. Dalam kegiatan ini juga beberapa ibu-ibu PKK turut serta membawa anaknya.

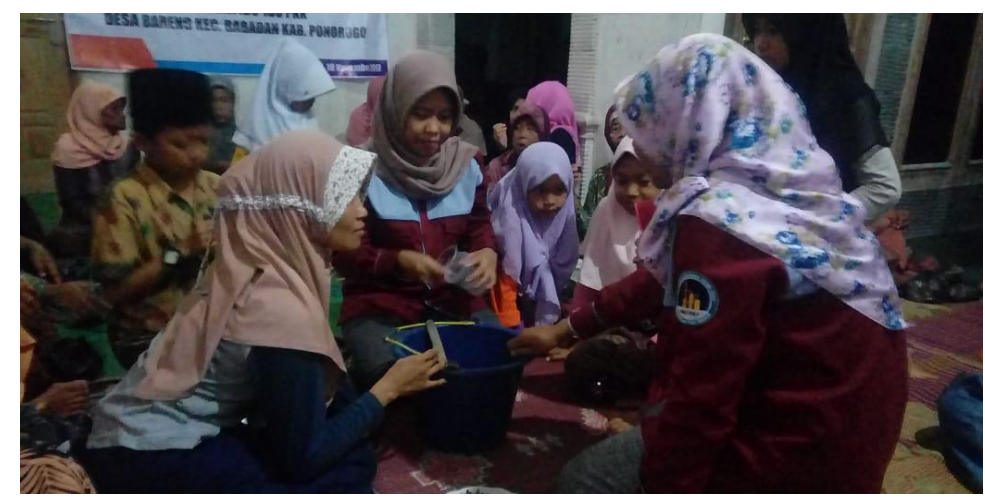

Gambar 2. Proses Pembuatan Sabun 
Dari Gambar 2 terlihat bahwa kelompok mitra sangat aktif mengikuti kegiatan ini. Mereka langsung menanyakan kepada tim pengabdi mengenai hal-hal yang belum mereka pahami dalam kegiatan pengabdian kepada masyarakat ini.

Setelah praktik pembuatan sabun cuci piring, tim pengabdi melakukan dokumentasi sesi foto bersama dengan kelompok mitra seperti yang ditunjukkan pada Gambar 3.

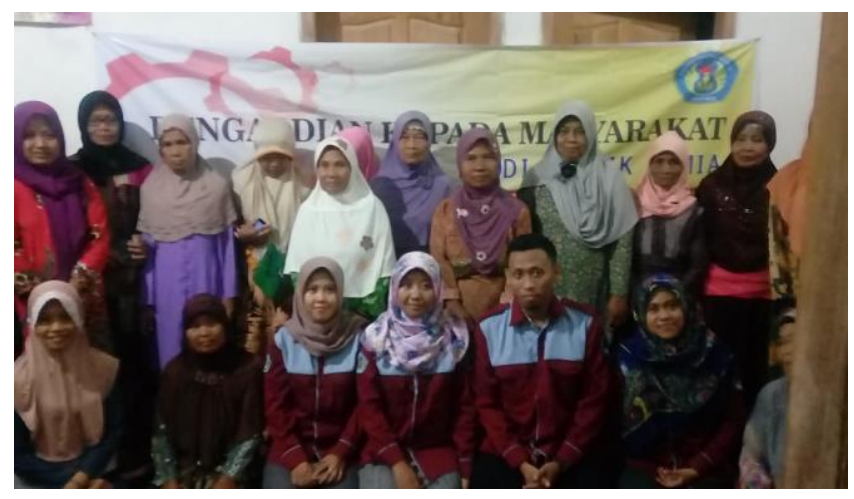

Gambar 3. Tim Pengabdi dan Kelompok Mitra

Pengemasan produk yang ditawarkan adalah dengan memanfaatkan botol bekas air mineral yang tidak digunakan. Botol tersebut telah dicuci dan keringkan. Setelah itu, botol dilabeli dengan label yang telah disiapkan oleh tim pengabdi. Produk sabun cuci piring yang dihasilkan ditunjukkan pada Gambar 4.

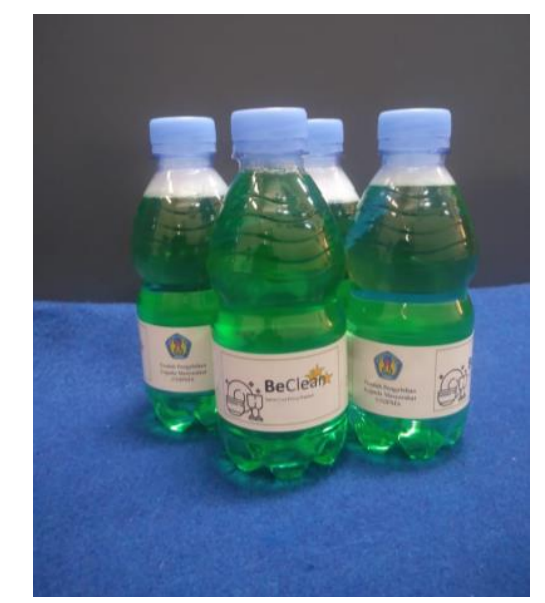

Gambar 4. Produk Sabun Cuci Piring

\section{ULASAN KARYA}

Dalam kegiatan pengabdian kepada masyarkat ini para ibu-ibu PKK sangat terbantu dan termotivasi dengan adanya kegiatan ini. Mereka mendapatkan pengetahuan tentang peluang usaha rumahan maupun keterampilan pembuatan sabun cuci piring. Selain itu, mereka menjadi termotivasi untuk berwirausaha mandiri di sela-sela kesibukan mereka sebagai ibu rumah tangga. Akan tetapi, pengetahuan kelompok mitra tentang bahan kimia baik mengenai sifat fisik, sifat kimia, penyimpanan maupun penggunaan masih minim sehingga membutuhkan pendampingan dari tim pengabdi pasca kegiatan pengabdian kepada masyarakat ini. 


\section{DAMPAK DAN MANFAAT KEGIATAN}

Banyak manfaat yang diperoleh dari kegiatan pengabdian kepada masyarakat ini, baik untuk tim pengabdi maupun kelompok mitra. Bagi tim pengabdi, kegiatan ini merupakan salah satu bentuk tridharma pendidikan sebagai kontribusi nyata untuk memberikan solusi terhadap permasalahan masyarakat sekitar. Sedangkan bagi kelompok mitra, kegiatan ini memberikan manfaat yang sangat besar bagi para ibu-ibu PKK di Desa Jetis Kabupaten Ponorogo. Mereka dapat memanfaatkan sabun cuci piring yang mereka produksi untuk kebutuhan sehari-hari sehingga dapat menghemat pengeluaran keluarga. Selain itu, mereka dapat menciptakan lapangan kerja baru dengan berwirausaha mandiri memproduksi sabun cuci piring.

\section{KESIMPULAN}

Kegiatan pelatihan pembuatan sabun cuci piring di Desa Jetis Kabupaten Ponorogo telah terlaksana sesuai dengan rencana. Ibu-ibu PKK dari masing-masing yakni RT 2 dan RT 3 telah berpartisipasi dan berperan aktif dalam kegiatan pengabdian kepada masyarakat ini. Mereka telah memiliki keterampilan pembuatan sabun cuci piring. Hasil kegiatan ini berupa produk sabun cuci piring yang dikemas dan dibagikan kepada warga sekitar.

\section{DAFTAR PUSTAKA}

[1] A. Widyasanti, A. Y. Rahayu, and S. Zein, "PEMBUATAN SABUN CAIR BERBASIS VIRGIN COCONUT OIL (VCO) DENGAN PENAMBAHAN MINYAK MELATI (Jasminum sambac) SEBAGAI ESSENTIAL OIL," $J$. Teknotan, vol. 11, no. 2, p. 1, 2017, doi: 10.24198/jt.vol11n2.1.

[2] 朱 晓 1 , 邹雪华 1 , 陈天虎 1 , 颜 玲 2 , 刘海波 1 , 李 平 1, “No Title: 黄铁矿一针铁矿混合无氧焙烧产物物相演变和特性,” vol. 3, no. 1, pp. 2834, 2014.

[3] A. Firdaus, "Pemberdayaan Ekonomi Ibu-Ibu Pkk Melalui," vol. 1, no. 1, pp. 7-12, 2020, [Online]. Available: http://digilib.uinsby.ac.id/44544/.

[4] E. S. VH and E. Susilowati, "Pemberdayaan Ibu-Ibu PKK Melalui Pelatihan dan Pendampingan Produksi sabun dan Deterjen," SEMAR J. Ilmu Pengetahuan, Teknol. dan Seni bagi Masy., vol. 4, no. 2, pp. 87-96, 2016.

[5] A. Gusviputri, N. Meliana, Aylianamawati, and N. Indraswati, "Pembuatan Sabun dengan Lidah Buaya (Aloe vera) sebagai Antiseptik Alami," Widya Tek., vol. 12, no. 1, pp. 11-21, 2013.

[6] H. A. Nasution and F. Zebua, "Kewirausahaan Peserta Didik Di Mas Al-Washliyah Desa Pakam,” vol. 1, no. 1, 2019.

[7] R. Amalia, V. Paramita, H. Kusumayanti, W. Wahyuningsih, M. Sembiring, and D. E. Rani, "Produksi Sabun Cuci Piring Sebagai Upaya Peningkatkan Efektivitas Dan 
Peluang Wirausaha," Metana, vol. 14, no. 1, p. 15, 2018, doi: 10.14710/metana.v14i1.18657.

[8] D. Rakhmawati, M. Rheza, R. Putra, and K. Asrihah, "Pelatihan Pembuatan Sabun Cuci Piring Bagi Ibu Rumah Tangga Di Desa Pamijen Sokaraja Sebagai Cara Penghematan Pengeluaran Bulanan," vol. 1, no. 2, pp. 103-110.

[9] P. Pembuatan and S. Cair, "DI KELURAHAN BUNULREJO KOTA MALANG," pp. 33-35.

[10] S. Pasir et al., "Penyuluhan dan praktik pembuatan sabun cuci piring cair 1," vol. 3, no. 3, pp. 155-159, 2014. 